\title{
Political Agency and Implementation Subsidies with Imperfect Monitoring*
}

\author{
Benjamin Blumenthal ${ }^{\dagger}$
}

January 2022

\begin{abstract}
Voters are frequently ill-equipped to monitor politicians' actions. Politicians are expected to implement projects, whose benefits sometimes partially accrue to interest groups and not entirely to voters. Interest groups thus have an incentive to affect which projects politicians implement, by providing implementation subsidies to lower the cost of policy-making that has to be borne by politicians. This paper shows how these considerations interact in a two-period political agency model with moral hazard and adverse selection. I study how the involvement of interest groups in the policy-making process can affect voters' welfare. I also show why voters might rationally not perfectly monitor politicians in the presence of interest groups that might capture projects' benefits and affect policy-making.
\end{abstract}

Keywords: political agency, interest groups, lobbying, rational ignorance.

JEL codes: D72, D73, D83

\footnotetext{
${ }^{*}$ I am grateful to the co-editor (Abraham Wickelgren), three anonymous referees, Bernard Caillaud, Arnaud Dellis, Dana Foarta, Simon Gleyze, Thomas Groll, Nikitas Konstantinidis, Antonin Macé, Clement Minaudier, Guillaume Pommey, Carlo Prato, Greg Sasso, Keith Schnakenberg, Ken Shotts, Federico Trombetta, Oliver Vanden Eynde, Thierry Verdier, Stephane Wolton, Antoine Zerbini, and Galina Zudenkova for very useful comments. I also thank participants of the Columbia/UQAM/CSDS Workshop on Interest Groups, the 20th Journées Louis-André Gérard-Varet at AMSE, the AFSE 2021 Annual Meeting, the Virtual Formal Theory Workshop, the MPSA 2021 Annual Meeting, the LSE PSPE informal seminar, the 14th RGS Doctoral Conference, and the PSE TOM and PhD seminars. A previous version of this paper was circulated under the title "Political Agency and Legislative Subsidies with Imperfect Monitoring". I thank the support of the EUR grant ANR-17-EURE-0001. All remaining errors are my own.

${ }^{+}$Paris School of Economics-EHESS, email: benjamin.blumenthal@mail.huji.ac.il.
} 


\section{Introduction}

Policy-making is a costly process, as politicians have to expend time and effort to implement new projects, such as the drafting of a new piece of legislation or the provision of public goods. These projects produce benefits, but the distribution of these benefits depends on how projects are implemented. In some cases voters and interest groups have conflicting preferences over implementation processes, since some of these split a given project's benefits in a more favourable way towards voters rather than towards interest groups. To illustrate the idea, consider the case of a bill introduced to create a new market or expand an existing one: it can be written in a way that is most favourable to consumers or it can provide benefits to consumers while simultaneously carving out some loopholes for involved firms that enable them to extract some rents from the market. Interest groups thus sometimes have an interest in providing implementation subsidies, which amount to reducing the cost of policy-making for politicians, to induce the implementation of projects in ways that favour them. Politicians can then accept the implementation subsidies offered or refuse them and implement, or not, a project on their own, shouldering the entire cost of policy-making. Moreover, there is a widespread concern in both the general public and the academic literature about the impact interest groups have on voters' welfare, with many seeing interest groups' access to politicians as detrimental to voters.

In this paper, I build a political agency model with a representative voter and an interest group (IG henceforth) to study a number of questions related to these observations. The use of a political agency model allows me to jointly consider how politicians' actions are affected by the voter's expectations of their behaviour, as well as how the information derived by the voter from politicians' actions allows her to select politicians aligned with her interests. As a first step, I consider a benchmark in which the IG can't offer implementation subsidies and the monitoring level is exogenously given. I characterise the possible equilibria and rank them in terms of voter's welfare. In a second step, I study how policy-making and voter's welfare are affected by allowing the IG to intervene in the policymaking process by offering implementation subsidies. Finally, I consider how the voter monitors politicians in the presence of an IG that might capture some projects' benefits and offer implementation subsidies to office-holders.

This paper's political agency model is a two-period model with a moral hazard component, stemming from the voter's imperfect monitoring of politicians' actions, and an adverse selection component, which comes from heterogeneity in politicians' preferences. In the model, an incumbent politician has to pick an action in the first period. Between the two periods an election takes place and the voter gets the opportunity to reelect the incumbent or replace him with a randomly drawn challenger. In the final period, the office-holder gets to pick an action. The action in both periods is whether or not to implement a project, and if the project is implemented, which technology to use. There are two costly implementation technologies for politicians, called optimal and shady. The optimal technology ensures that the voter enjoys the entire value created by the project. The shady technology splits the project's value between the voter and the IG.

In the model, politicians come in two types, benevolent and strategic. Benevolent politicians always implement the project optimally. Strategic politicians gain some benefits from being in office and select their action to maximise their expected payoff, taking into account that the voter seeks to maximise her own payoffs and updates her beliefs rationally. She can observe whether the project 
has been implemented, but cannot necessarily tell whether it was implemented in the shady or the optimal way. This assumption reflects the fact that the details of a bill are often inscrutable for the layperson, whereas a bill's passing is more easily verifiable.

In the analysis, I use the term control to describe the extent to which a strategic incumbent distorts his first period action away from his favourite action towards an action more favourable to the voter and the term screening to describe the possibility for the voter to use the election as a tool to screen a benevolent incumbent from a strategic one. Depending on the value of holding office, the probability of revelation of the incumbent's action before the election, and the costs of shady and optimal implementation, the polity can be in one of three different equilibria: a slacking equilibrium, a pooling equilibrium, or a masquerading equilibrium.

In a slacking equilibrium, a benevolent politician implements optimally the project in each period, whereas a strategic politician does not implement the project in any period. This equilibrium is characterised by perfect screening, since a strategic incumbent is voted out. However, it is also characterized by no control, as a strategic incumbent does not implement the project at all in the first period. In a pooling equilibrium, both a benevolent incumbent and a strategic incumbent implement the project optimally in the first period, but only a benevolent politician implements (optimally) the project in the second period. This equilibrium is characterised by perfect control, since a strategic incumbent implements the project optimally in the first period. However, it is also characterised by no screening, since the voter is unable to screen a strategic incumbent from a benevolent incumbent. In a masquerading equilibrium, a benevolent politician implements the project optimally in both periods, whereas a strategic politician implements the project (shadily) only in the first period. This equilibrium is characterised by partial screening, as a strategic incumbent is not reelected if the implementation technology is revealed as shady, and by partial control, since a strategic incumbent implements the project shadily, thereby offering only a share of the project's full value to the voter.

The ranking of the different equilibria in terms of voter's welfare depends on the strength of the different screening and control effects, and the parameters that determine them: the likelihood that politicians are benevolent, the probability that the implementation technology is revealed prior to the election, and the share of the project's value that is appropriated by the IG in the shady process. The slacking equilibrium is always welfare dominated by the pooling equilibrium, but all other rankings between the three equilibria are possible depending on the parameter values.

I then allow the IG to intervene in the policy-making process by offering implementation subsidies to politicians, to share the implementation cost of projects. This can expand, for a suitable range of parameters, the set of values of the benefit of holding office for which the equilibrium is masquerading. Since the welfare ranking between the slacking, pooling, and masquerading equilibria depends on the strength of the partial control and partial screening effects in the masquerading equilibrium, the IG's involvement in the policy-making process can benefit or harm the voter, depending on the circumstances. This interaction of screening and control effects yield subtle results and dynamic effects must be taken into account to assess the welfare effects of interest groups' involvement in the policy-making process. These results speak to current debates about the desirability, for voters, of allowing interest groups to access politicians. I show that there might not be a straightforward relationship between voters' welfare and the involvement of interest groups in the policy-making process. The desirability of allowing interest groups to access politicians should be evaluated in the 
specific context in which such access would occur.

I subsequently endogenise the monitoring level. Such monitoring can come from an independent government watchdog agency, for instance. Endogenising the monitoring level then amounts to selecting the level of funding for the agency, prior to the policy-making process. I show that it is never optimal for the voter to perfectly monitor the office-holder when monitoring is costly. I first note that if the equilibrium is pooling or slacking, increasing the monitoring level does not affect a strategic office-holder's equilibrium strategy or the voter's welfare directly, and is hence detrimental for the voter, since it is costly. If the equilibrium is masquerading, increasing monitoring can be profitable to the voter depending on the cost of increased monitoring and the welfare ranking of the different equilibria. It remains however sub-optimal to monitor perfectly the politician. Additionally, I show that even when monitoring is costless, there are settings in which perfect monitoring is strictly worse for the voter than imperfect monitoring. This result relies on the strength of the partial control and partial screening effects in a masquerading equilibrium and the assumption that the voter's monitoring decision occurs before the incumbent's first period action: provided that the voter's welfare in a masquerading equilibrium is sufficiently high, the voter can be better off not monitoring perfectly the politician.

I view the contribution of this paper as twofold: first, I show how interest groups' involvement in policy-making can affect voters' welfare through a dynamic screening effect and a static control effect, in a setting where interest groups might capture some of the benefits of policy-making at the voters' expense. I characterise when such involvement is beneficial or harmful to voters. Moreover, I show that an alignment of interests (resp. opposition of interests) between interest groups and voters need not imply that the former's involvement in the policy-making process is beneficial (resp. harmful) to voters. This provide a novel rationale for the harm that voters can incur (resp. the benefits voters can derive) from the involvement of interest groups in policy-making, even when their interests are aligned (resp. opposed). Second, I use the model to explore how voters monitor politicians, and provide a formal micro-foundation for the well documented phenomenon of voters' rational ignorance about policy-making. I show how, when monitoring is costly or even costless, voters might rationally elect not to monitor politicians perfectly.

\section{Literature review}

This paper contributes to three main strands of the literature. First, it contributes to the political agency literature, and in particular to papers in that literature that combine moral hazard and adverse selection (early important contributions include Coate and Morris (1995) and Fearon (1999); for overviews, see Besley (2006), Ashworth (2012), and Duggan and Martinelli (2017)). In this paper, politicians differ in their preferences: benevolent politicians care about the voter's welfare, whereas strategic politicians care about themselves. In this literature, the closest papers to this one are Besley and Smart (2007), Ashworth and Bueno de Mesquita (2014), Fox and Stephenson (2015), Wolton (2019), and Blumenthal (2021). In these papers, the authors describe conditions under which being less informed can be beneficial for voters, which is also a crucial feature of the model I build. The mechanism, a trade-off between the screening and control of politicians, is similar to the one in these papers, but the specifics differ (Blumenthal (2021) provides an overview of the mechanism which underpins some 
important results in these papers). I focus here on the role of interest groups in policy-making and endogenous monitoring by the voter, two crucial features that are not present in these papers. Doing so allows me to derive some new normative implications about when interest groups' involvement in the policy-making process benefits or harm voters. In addition, I can provide some sharp results about endogenous monitoring of office-holders by voters when interest groups can provide implementation subsidies and extract some rents from the policy-making process at the voters' expense.

Second, the paper contributes to the literature on information and transparency in decisionmaking or policy-making. There are two broad strands to this literature: first, there are a number of papers on the costs and benefits of transparency over actions (Prat (2005), Fox and Van Weelden (2012), $\mathrm{Fu}$ and Li (2014), Fox (2007)). The two first papers consider the case of a privately informed agent with knowledge about the adequacy of a policy for a principal's welfare and consider the incentives for the agent to pander towards the ex-ante more desirable policy. The third paper considers how different transparency rules affect the incentives of low-ability politicians to carry out reforms which they are ill-equipped to implement. In contrast, I consider a setting with costly effort in which politicians (agents) differ in their preferences and not in their ability, which is closer to Fox (2007). In addition, there is no room in the model for expertise or conformism, since politicians either implement a project or not. The transparency in my model is about how a project is implemented and is modelled as the probability that the voter becomes informed about the technology used by a politician.

Since I consider an endogenous level of transparency in parts of the paper, my paper is also close to a second, burgeoning strand of the literature that focuses on endogenous attention in politics. In contrast with Matejka and Tabellini (2021) which focuses on a political competition setting with probabilistic voting and considers the incentives of groups of voters with heterogeneous preferences to acquire more precise information about policies offered by candidates, I consider a two-period political agency model with moral hazard and adverse selection, with no differences of interests between voters (hence the use of a representative voter framework). This makes my work closer to the papers of Prato and Wolton (2016), Prato and Wolton (2018), Trombetta (2020), and Devdariani and Hirsch (2021). The former two consider models of electoral competition with a representative voter, whilst the latter two focus on political agency models of pandering with a representative voter. In this paper, I show two main results on monitoring policy-making: first, under a fairly general specification, if increasing the monitoring level is costly, perfect monitoring of politicians' actions is never optimal for the voter. Second, I show that even if increasing the monitoring level is costless, perfect monitoring can be strictly worse for the voter than imperfect monitoring. These results do not depend on the IG's ability to provide implementation subsidies.

Finally, this work contributes to the literature on lobbying and the role of interest groups in the policy-making process (for an overview of the early work on the topic, see Grossman and Helpman (2001)). Among the closest papers to this one are Schnakenberg and Turner (2019), Hall and Deardorff (2006), Ellis and Groll (2020), Hirsch and Shotts (2015), and Hirsch and Shotts (2018). My use of implementation subsidies borrows both from the contributions of Hall and Deardorff (2006) and Ellis and Groll (2020), since in my model the IG can subsidise the cost of implementing a project for a politician by exploiting their congruence of interests, and from Hirsch and Shotts (2015) and Hirsch and Shotts (2018), since the IG's contribution is targeted towards a specific project, giving the IG the power to select a specific project. Compared to Schnakenberg and Turner (2019), which discusses the 
potential benefits and costs of access for voters when an interest group can offer bribes or information, I study the interaction of static control and dynamic screening consequences of an interest group's involvement in policy-making. This hitherto understudied mechanism highlights a different way through which voters' welfare can be affected by the involvement of interest groups in policy-making. In addition, I consider the issue of voters' monitoring of office-holders in a setting where interest groups might extract some benefits of the policy-making process at the voters' expense and provide implementation subsidies to office-holders, and show that imperfect monitoring is strictly better than perfect monitoring for voters when monitoring is costly. Moreover I show that even if monitoring is costless, imperfect monitoring can be strictly better than perfect monitoring.

\section{Baseline model}

The baseline model focuses on a two-period interaction between an incumbent ( $\mathrm{I}$ - he), a challenger ( $\mathrm{C}$ also a he), a representative voter (V - she), and an IG (it). In each period, a project can be implemented, either in an optimal way or in a shady way. To make matters more concrete, I use as a running example the situation described in the introduction: a bill might be introduced to create a new market or to further expand an already existing one. By passing the bill, some value would be created, the allocation of which depends on the contents of the bill. It can be written in a way that is most favourable to consumers, which corresponds to an optimal implementation of the project; alternatively, it can carve out some loopholes for involved firms, along with benefits for consumers, which corresponds to a shady implementation of the project.

Timing. First, Nature draws the politicians' types, $\tau_{i} \in\{b, \sigma\}$ (benevolent or strategic) with $i=\{\mathrm{I}, \mathrm{C}\}$. The common knowledge prior probability that a politician is benevolent is $\pi:=\operatorname{Pr}\left[\tau_{i}=\right.$ b], with $\pi \in(0,1)$. A politician's type is his own private information. The incumbent then gets an opportunity to implement a project, using one of the two technologies at his disposal. The voter observes whether the project was implemented and, possibly, an informative signal about the technology used. Following these signals, the voter either reelects the incumbent or replaces him with the challenger. The second period office-holder gets an opportunity to implement a project using one of the two technologies at his disposal. The voter's payoff is realised as the game ends. ${ }^{1} \mathrm{I}$ assume that players value the present and the future the same way. ${ }^{2}$

Actions, preferences, and informational structure. I express the two possible implementation technologies as the cost that must be expended to implement the project. In the optimal implementation process, a finite amount $\kappa_{\mathrm{o}}>0$ has to be invested in the project's implementation and the voter benefits from the project's full finite value $\mu>0$. In the shady implementation process, a finite amount $\kappa_{\mathrm{s}}>0$ has to be invested in the project's implementation and the value of the project $\mu$ is shared between the voter, who gets a share $\alpha$ of it, and the IG, which gets a share $1-\alpha$ of it, with $\alpha \in(0,1){ }^{3}$

\footnotetext{
${ }^{1}$ The assumption that the voter's payoff is realised as the game ends is crucial for most of the paper's results. It is a standard assumption in many two-period political agency models (see Fox (2007) or Canes-Wrone, Herron and Shotts (2001) for instance), and is consistent with an interpretation of a lag between the implementation of a project and the realisation of all its benefits. For an additional discussion of the issue, see footnote 5 .

${ }^{2}$ The assumption regarding the weighing of the present versus the future is not consequential. So long as players do not value only the future or the present, qualitatively similar results would hold. See Ashworth and Bueno de Mesquita (2014) for a related discussion.

${ }^{3}$ The IG's indifference between no implementation and optimal implementation simplifies the exposition in the implementation subsidies section, but is not crucial to the results.
} 
Politicians come in two types: benevolent and strategic. Bribes are not allowed in the model, but strategic politicians value being in office, a finite value denoted $W>0$. A strategic politician's utility in every period is equal to 0 when out of office and to the difference between the benefit from being in office $(W)$ and the incurred effort cost when in office. A strategic politician's total payoff is given by the sum of his per-period payoffs. Benevolent politicians are a behavioural type: they implement optimally the project in every period.

The voter's only action in the baseline model is to decide whether to reelect the incumbent or vote for the challenger. To guide her decision, the voter can rely on some observation of the incumbent's action: whether or not the project is implemented is always observed publicly. ${ }^{4}$ Moreover, the technology used is observed only with probability $\varepsilon \in(0,1)$ (conditional on the project being implemented). ${ }^{5}$

Equilibrium concept. My solution concept is Perfect Bayesian Equilibrium (equilibrium henceforth). To characterise an equilibrium, I have to specify the strategic politicians' and representative voter's equilibrium strategies and the voter's equilibrium beliefs. A strategies-belief pair is an equilibrium if (1) the strategic politicians' equilibrium strategy maximises their expected payoff given the voter's equilibrium beliefs and strategy, (2) the voter's equilibrium strategy maximises her expected payoff given her equilibrium beliefs and the strategic politicians' equilibrium strategy and (3) for each possible observation of the incumbent's action, the voter's posterior belief that the incumbent is benevolent - $\hat{\pi}_{\mathrm{I}}$ - is derived via Bayes' Rule.

Modelling assumptions. The choice of a two-period model provides a tractable way to model the interplay between politicians' short-term opportunistic incentives and long-term reelection incentives (Duggan and Martinelli (2020)). It also provides a simple framework in which to consider delayed observation of office-holders' performance and study how it affects the voter's welfare.

The two technologies' costs $\kappa_{\mathrm{s}}$ and $\kappa_{\mathrm{o}}$ need not be equal and I make no assumption on whether one is greater than the other. Depending on the particular case at hand, it is possible to imagine one or the other being the lowest. Consider again the example of a bill introduced to create a new market or expand an existing one. Suppose that to follow the rules, a politician has to spend a lot of time preparing the groundwork for the bill and, for instance, organise a consultation of the different stakeholders that would be affected by the bill. It could then be less costly for a politician to directly collude with the involved firms to fix things beforehand, without resorting to officially sanctioned processes. Alternatively, it might be that the politician would have to spend a great deal of time and effort to write the bill in a way that allows the involved firms to extract some rents from it without it being obvious to a government watchdog agency or the media. In that case, writing the bill in the way that is most favourable to voters would be cheaper for him.

Abstracting from any adverse selection or moral hazard issues, the voter prefers the project's optimal implementation over its shady implementation, and both over its non-implementation, since $\alpha \in(0,1)$. This is an important difference with Coate and Morris (1995), where a public good's provision in a "shady" way can be detrimental to the voter. There are two main alternatives to this

\footnotetext{
${ }^{4}$ This assumption is without loss of generality qualitatively.

${ }^{5}$ An alternative interpretation of the $\varepsilon$ parameter is to see it, at least partly, as the probability that the voter's first period payoff is realised prior to the election. In that interpretation, the technology need not be observed directly by the voter, but the voter can infer from the observation of his payoff whether the project was implemented shadily or optimally, depending on whether his first period payoff is $\mu$ or $\alpha \times \mu$.
} 
assumption. The first one would be to consider that shady implementation is worse for the voter than no implementation, with optimal implementation remaining the best for the voter. In that case, all of the equilibrium characterisations that follow would remain valid. However, welfare analyses would be affected. ${ }^{6}$ A second possibility would be to consider that both shady and optimal implementation are worse for the voter than no implementation. In that case, the premise of the model would be affected: indeed, having benevolent politicians implement the project optimally wouldn't make sense anymore, since this wouldn't be optimal for the voter. A more natural assumption in that case would be to consider that benevolent politicians don't implement any project. The analysis of such a modified model would then be trivial and wouldn't yield any interesting insights, as strategic politicians wouldn't implement projects either, since implementation is costly and ensures non-reelection.

For some set of parameter values of measure zero, there are multiple equilibria. ${ }^{7}$ To simplify the exposition by ensuring the existence of a unique equilibrium, I make the following assumptions: first I select the IG preferred equilibrium, and if there are still multiple equilibria, I select the voter preferred equilibrium. This assumption is consistent with lexicographic preferences for the strategic politician: his first goal is to maximise his own payoff. Given a level of payoff for him, he then selects the strategy which maximises the IG's payoff; finally, given a level of payoff for him and for the IG, he selects the strategy which maximise the voter's welfare. ${ }^{8}$ Finally, to simplify the exposition, I assume that when indifferent between voting for the incumbent and voting for the challenger, the voter reelects the incumbent with probability $1 .^{9}$

\subsection{Equilibrium characterisation and welfare analysis}

Equilibrium characterisation. A politician's reputation only matters for the possibility of reelection. Since he can't be reelected, a second period strategic office-holder does not care about being exposed as strategic: he does not implement the project, as both technologies are costly. This yields the following lemma:

Lemma 1. A second period strategic office-holder does not implement the project.

Given Lemma 1, the assumption that the voter votes for the incumbent if she is indifferent between him and the challenger, and denoting $\hat{\pi}_{\mathrm{I}}$ the voter's posterior belief on the incumbent's likelihood of being benevolent given what the voter observes prior to the election, this yields:

Lemma 2. The voter's reelection rule is:

$$
\mathrm{R}= \begin{cases}1 & \text { if and only if } \hat{\pi}_{\mathrm{I}} \geqslant \pi \\ 0 & \text { otherwise }\end{cases}
$$

Using the results of the two preceding lemmas, I can characterise a strategic incumbent's first

\footnotetext{
${ }^{6}$ Shady implementation would provide a much lower level of control than optimal implementation and lower levels of control and screening than no implementation.

${ }^{7}$ This includes equilibria with mixed strategies, as discussed further in the proof of Proposition 1 in the Appendix

${ }^{8}$ This assumption also simplifies the analysis in the model with implementation subsidies; the IG only has to make the politician indifferent between shady implementation and one of the two other options.

${ }^{9}$ The model is qualitatively robust to any change in the probability of reelection in the case of indifference such that the incumbent is reelected with strictly positive probability in that case.
} 
period equilibrium strategy. A strategic incumbent's goal is to maximise his total expected payoff. ${ }^{10}$ Comparing the value for a strategic incumbent of the three available strategies and applying the equilibrium selection rule in cases of indifference yields the following proposition:

Proposition 1. In all three possible equilibria the voter's and second period strategic office-holder's equilibrium strategies are as described in Lemma 2 and Lemma 1. A strategic incumbent's first period equilibrium strategy and voter's beliefs in equilibrium are as follows:

1. In a slacking equilibrium, a strategic incumbent does not implement the project in the first period. Both strategic and benevolent incumbents are correctly identified by the voter prior to the election.

2. In a masquerading equilibrium, a strategic incumbent implements the project with the shady technology in the first period. With probability $\varepsilon$, both strategic and benevolent incumbents are correctly identified by the voter prior to the election. With probability $1-\varepsilon$, the voter does not learn the incumbent's type prior to the election.

3. In a pooling equilibrium, a strategic incumbent implements the project optimally in the first period. The voter does not learn the incumbent's type prior to the election.

The conditions under which each equilibrium exists are as follows:

1. If $\mathrm{\kappa}_{\mathrm{o}}<\frac{\mathrm{\kappa}_{\mathrm{s}}}{1-\varepsilon}$ : for all $\mathrm{W}<\mathrm{\kappa}_{\mathrm{o}}$, the unique equilibrium is slacking; and for all $\mathrm{W} \geqslant \mathrm{\kappa}_{\mathrm{o}}$, the unique equilibrium is pooling.

2. If $\mathrm{\kappa}_{\mathrm{o}} \geqslant \frac{\mathrm{K}_{\mathrm{s}}}{1-\varepsilon}$ : for all $\mathrm{W}<\frac{\mathrm{K}_{\mathrm{s}}}{1-\varepsilon}$, the unique equilibrium is slacking; for $\frac{\mathrm{K}_{\mathrm{s}}}{1-\varepsilon} \leqslant \mathrm{W} \leqslant \frac{\mathrm{K}_{\mathrm{o}}-\mathrm{K}_{\mathrm{s}}}{\varepsilon}$ the unique equilibrium is masquerading; and for all $\mathrm{W}>\frac{\mathrm{K}_{\mathrm{o}}-\mathrm{K}_{\mathrm{s}}}{\varepsilon}$, the unique equilibrium is pooling.

Figure 1 provides a graphical representation of Proposition 1. The blue lines represent the strategic incumbent's payoff from optimal implementation, whereas the red lines correspond to the strategic incumbent's expected payoff from shady implementation. The strategic incumbent's payoff from no implementation is equal to 0 . The pale orange areas correspond to the range of values of $W$ for which the equilibrium is slacking. The blue area corresponds to the range of values of $W$ for which the equilibrium is masquerading. The purple areas correspond to the range of values of $W$ for which the equilibrium is pooling.

To provide some intuition for the different equilibria, assume first that $\kappa_{\mathrm{o}}<\frac{\kappa_{\mathrm{s}}}{1-\varepsilon}$. In that case, shady implementation is strictly worse for a strategic incumbent than either no implementation, optimal implementation, or both, for all possible values of $W$ (as can be seen in Figure 1). When $W<\kappa_{0}$, a strategic incumbent's payoff from no implementation is strictly higher than his payoff from optimal implementation: office rents that would be earned by being reelected are too low compared to the cost of optimal implementation. When $W>\kappa_{o}$ a strategic incumbent's payoff from optimal implementation is strictly higher than his payoff from no implementation: office rents that would be earned by being reelected are high enough compared to the cost of optimal implementation. ${ }^{11}$

\footnotetext{
${ }^{10}$ This is a slight language abuse. Instead of his total expected payoff, a strategic incumbent maximises his expected payoff at the point at which he has the opportunity to implement a project, i.e. I do not take into account office rents from being in office in the first period, since they do not affect a strategic incumbent's behaviour and consequently do not affect the voter's reelection decision.

${ }^{11}$ The case where $W=\kappa_{o}$ is slightly different: a strategic incumbent's payoff from optimal implementation is equal to his payoff from no implementation. The equilibrium selection rule (namely the selection of the voter's preferred equilibrium) ensures the selection of optimal implementation as the unique equilibrium strategy.
} 


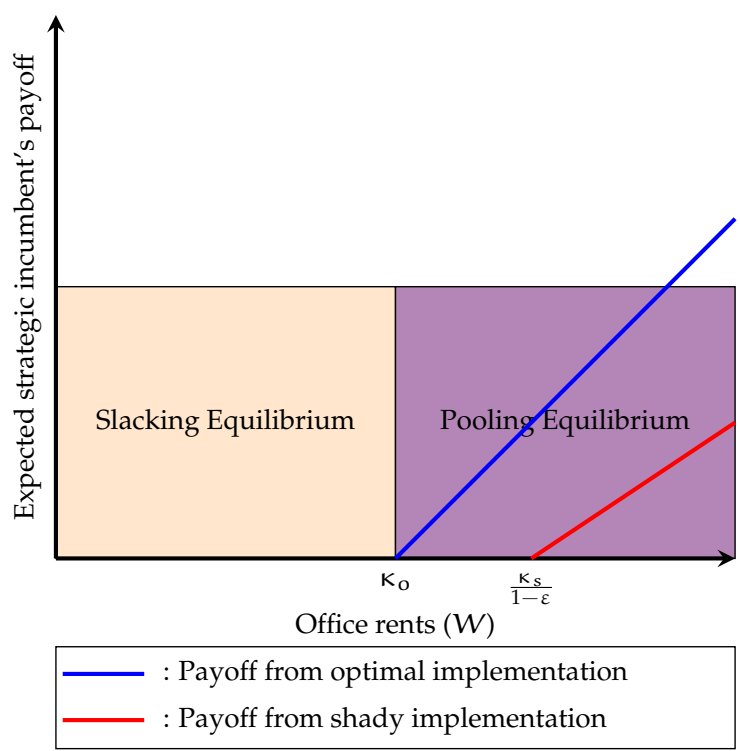

(a) $\kappa_{\mathrm{o}}<\frac{\mathrm{K}_{\mathrm{s}}}{1-\varepsilon}$

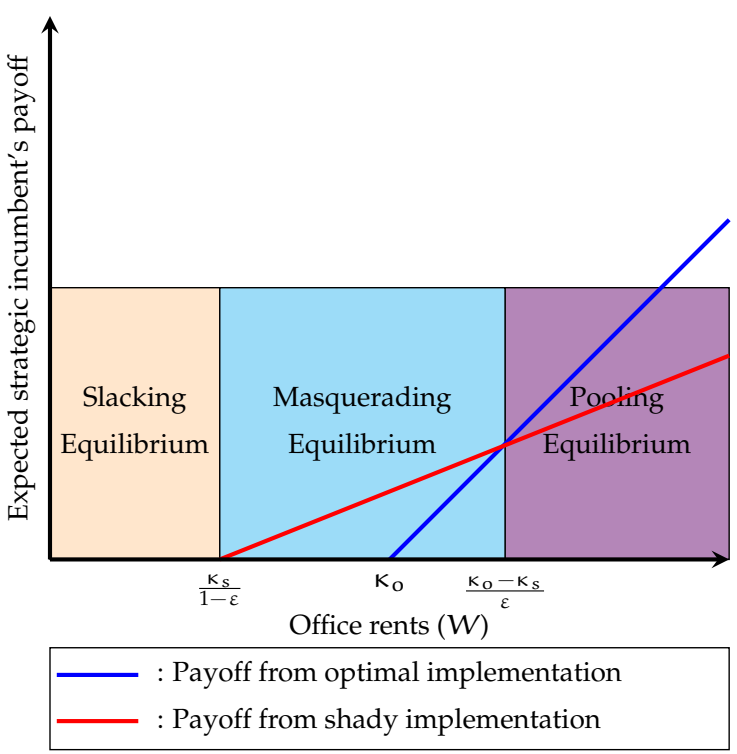

(b) $\kappa_{\mathrm{o}}>\frac{\kappa_{\mathrm{s}}}{1-\varepsilon}$

Figure 1: Baseline model

Next, assume that $\kappa_{0} \geqslant \frac{k_{s}}{1-\varepsilon}$. If this holds, there exist a range of values of $W$ (possibly a singleton) for which the unique equilibrium is neither slacking nor pooling, but rather masquerading. This masquerading equilibrium exists only for an intermediate range of $W$ (as can be seen in Figure 1). There are three relevant ranges: when the value of holding office is low (if $W<\frac{K_{s}}{1-\varepsilon}$ ), both shady implementation and optimal implementation are too costly for a strategic incumbent compared to the value of holding office in the subsequent period, and a strategic incumbent refrains from implementing the project in the first period. When the value of holding office is intermediate (if $\frac{\kappa_{s}}{1-\varepsilon} \leqslant W \leqslant \frac{K_{0}-K_{s}}{\varepsilon}$ ) a strategic incumbent selects shady implementation: first, the expected benefit of holding office in the subsequent period outweighs the cost of shady implementation, despite the possibility of revelation of the implementation technology. He thus prefers Shady implementation to no implementation. Second, even though the reelection probability for a strategic incumbent with shady implementation is strictly less than 1 , the difference in costs between shady implementation and optimal implementation ensures that a strategic incumbent prefers shady implementation over optimal implementation. ${ }^{12}$ Graphically, this corresponds to the region of the right panel of Figure 1 in which the red line (the strategic incumbent's expected payoff from shady implementation) is strictly above the blue line (the strategic incumbent's payoff from optimal implementation) and strictly above the horizontal axis (the strategic incumbent's payoff from no implementation). Finally, when the benefit from holding office in the subsequent period is high (when $\frac{\kappa_{0}-k_{s}}{\varepsilon}<W$ ), the risk of not being reelected for a strategic incumbent by selecting shady implementation trumps the advantage that shady implementation holds because of its lower cost compared to optimal implementation, and a strategic incumbent optimally implements the project in the first period.

Put differently, imperfect monitoring is a necessary condition for the existence of a masquerading equilibrium. Moreover, a masquerading equilibrium can exist only if shady implementation is less costly than optimal implementation, as shady implementation is more risky than optimal

\footnotetext{
${ }^{12}$ These intuitions do not hold for the boundary points of measure zero, where the payoffs of two or three actions are equal and where the equilibrium selection rule plays a role, as discussed in footnote 11 and the proof of Proposition 1.
} 
implementation: reelection is not guaranteed for the former, whereas it is guaranteed for the latter.

Welfare analysis. The differences in welfare between the different equilibria stem from differences in a strategic incumbent's equilibrium strategy and differences in the information available to the voter for her reelection decision. Recall that I use the term control to describe the extent to which a strategic incumbent distorts his first period action away from his favourite action towards an action more favourable to the voter and the term screening to describe the possibility for the voter to use the election as a tool to screen a benevolent incumbent from a strategic one. The following proposition provides a ranking of the different equilibria in terms of the level of voter's welfare:

Proposition 2. 1 . The voter's ex-ante welfare is higher in the masquerading equilibrium than in the pooling equilibrium when $\alpha+\varepsilon \times \pi>1$.

2. The voter's ex-ante welfare is higher in the masquerading equilibrium than in the slacking equilibrium when $\alpha+\varepsilon \times \pi>\pi$

The voter's ex-ante welfare in the different equilibria can be decomposed in three components that represent the level of control, the level of screening, and the value of screening in each equilibrium. The level of control corresponds to the voter's expected first period welfare; the level of screening corresponds to the ex-ante probability of a benevolent second period office-holder; and the value of screening corresponds to the difference between the voter's second period welfare under a benevolent office-holder and under a strategic office-holder. ${ }^{13}$

Consider first the levels of control in the different equilibria. In the first period in a pooling equilibrium, both benevolent and strategic incumbents implement optimally the project, yielding a first period expected payoff of $\mu$ to the voter. In the first period in a masquerading equilibrium, a benevolent incumbent implements optimally the project, whilst a strategic incumbent implements the project with the shady technology, yielding a first period expected payoff of $\pi \times \mu+(1-\pi) \times \alpha \times \mu$ to the voter. In the first period in a slacking equilibrium, a benevolent incumbent implements optimally the project, whilst a strategic incumbent does not implement the project, yielding a first period expected payoff of $\pi \times \mu$ to the voter. Thus, there is full control in a pooling equilibrium, partial control in a masquerading equilibrium given that $1>\alpha>0$, and no control in a slacking equilibrium.

Consider next the levels of screening in the different equilibria. In a pooling equilibrium, both benevolent and strategic incumbents are reelected for the second period, yielding an ex-ante probability of a benevolent second period office-holder of $\pi$. In a masquerading equilibrium, a benevolent incumbent is necessarily reelected, whilst a strategic incumbent is reelected only if the technology is not revealed, yielding an ex-ante probability of a benevolent second period office-holder equal to $\pi+(1-\pi) \times \varepsilon \times \pi$. In a slacking equilibrium, a benevolent incumbent is necessarily reelected, whilst a strategic incumbent is not reelected, yielding an ex-ante probability of a benevolent second period office-holder equal to $\pi+(1-\pi) \times \pi$. Thus, there is no screening in a pooling equilibrium, partial screening in a masquerading equilibrium given that $1>\varepsilon>0$, and full screening in a slacking equilibrium.

In all three equilibria, the value of screening is the same, given that a strategic second period office-holder does not implement the project and that a benevolent second period office-holder

\footnotetext{
${ }^{13}$ Blumenthal (2021) provides an overview of different political agency models in which a similar mechanism plays an important role.
} 
implements the project optimally: the difference between the voter's second period welfare under a benevolent office-holder and under a strategic office-holder is equal to $\mu$.

The crucial insight that emerges from this analysis of the welfare ranking of the different equilibria is that the masquerading equilibrium welfare dominates, under the appropriate conditions, the slacking equilibrium, the pooling equilibrium, or both. This happens when the strength of the partial control and partial screening effects in the masquerading equilibrium are sufficiently high, compared to the voter's ex-ante welfare in a pooling equilibrium or in a slacking equilibrium.

\section{Interest group and implementation subsidies}

\subsection{A modified model with implementation subsidies}

I modify the baseline model by allowing the IG to intervene in the policy-making process. The IG has a direct interest in having the project implemented shadily, since it benefits of a share $1-\alpha$ of its value in that case. Consider again the running example of the paper: firms have an interest in seeing the bill passed carve out loopholes for them that allow them to extract some of the benefits that are generated by the creation or the extension of the market. Thus they have an incentive to contribute to the cost of policy-making to affect the nature of the bill passed by office-holders

To model this formally, I assume that the IG gets the opportunity, prior to the office-holder's implementation decision, to make a take-it-or-leave-it offer to share the cost of effort required to implement the project. This is an implementation subsidy (Ellis and Groll (2020)). An offer takes the form of an amount $x$ that the IG offers to the politician and which can only be invested in a specific project's implementation. It reduces the cost for the politician, which becomes $\kappa_{j}^{p}=\kappa_{j}-x$, with $j \in\{0, s\} .{ }^{14}$ The IG's offer is necessarily targeted towards one or the other technology available (this approach is reminiscent of the assumption of policy specific quality in Hirsch and Shotts (2015) and Hirsch and Shotts (2018)). The IG's strategy has three components. First, the IG decides whether to offer a subsidy or not. Second, if it offers a subsidy, it has to select to which technology it targets it. Finally, it has to select the subsidy's amount.

Modelling assumptions. In the running example of the paper, an implementation subsidy corresponds to help offered to office-holders by involved firms that would benefit from the passing of a bill opening a new market or expanding an existing one. This help can take many forms: it could take the form of legal drafting of the bill or amendments for office-holders, reducing the (costly) effort they have to put in in order to pass a bill. Alternatively, it could correspond to information campaigns, or could cover some of the development costs.

I assume that full subsidisation is not possible: the politician has to expend himself at least $\underline{\kappa_{j}}>0$ to implement a project. The other alternative would be to assume that full subsidisation is possible. I do not go with this alternative route for reasons of both robustness and verisimilitude: the existence of a strictly positive lower bound on the level of effort an office-holder has to expend to implement a project is fairly flexible. This cost can be extremely low, but that it is greater than 0 makes it non-knife-edge; consider again the case of a bill. A policymaker still has to take some action

\footnotetext{
${ }^{14}$ An alternative approach would be to specify an implementation subsidy as a share of the value of the cost, instead of as a difference, but it would lead to qualitatively equivalent results.
} 
on his own that the IG cannot subsidise, for instance sitting in the chamber and voting in favour of the bill. Accordingly, the IG's offer can be at most an offer of $x_{\mathrm{o}}^{\max }=\kappa_{\mathrm{o}}-\underline{\kappa_{0}}$, if targeted towards optimal implementation, or of $x_{s}^{\max }=\kappa_{s}-\underline{\kappa}_{s}$, if targeted towards shady implementation. I assume that $(1-\varepsilon) \kappa_{\mathrm{o}}>\underline{\kappa}_{\underline{s}} .{ }^{15}$

Implementation subsidies are distinct from bribes. Bribes can't be made contingent on the nature of the project implemented (since bribes are illegal, they can't be legally enforced by a third party). An alternative modelling strategy that would preserve the sequential nature of the game and would make implementation subsidies, as understood in this paper, closer to bribes would be to consider a sequential game in which the IG makes an offer first, with the offer being non targeted to one technology or the other. However, this alternative would be vulnerable to a standard commitment problem: an office-holder would then have an incentive to deviate to his preferred strategy, preventing implementation subsidies from having any effect in equilibrium.

Without loss of generality, I assume that when indifferent between an implementation subsidy and no implementation subsidy, the IG provides an implementation subsidy. In addition, an offer made by the IG that is refused by the politician still has to be paid for by the IG. To interpret this assumption, consider again the case of a bill: suppose that the involved firms provide to the officeholder some legal drafting, which is then not used by the office-holder, either because he prefers not to pass the bill, or because he prefers to pass a bill that does not make use of said legal drafting. In that case, the involved firms would have paid the cost for the drafting of the document, even though it is not used by the office-holder. ${ }^{16}$ Finally, I assume that the politicians' types are known to the IG. ${ }^{17}$

\subsection{Equilibrium}

Since benevolent office-holders follow a behavioural strategy and always implement projects optimally, the IG does not offer them any implementation subsidy in equilibrium. What remains to be seen is whether the IG has any incentives to offer implementation subsidies to strategic office-holders.

Consider first the incentives of a second period strategic office-holder. Recall that a second period strategic office-holder has no reputational concerns: he does not implement the project when the IG does not offer an implementation subsidy. The subsidy that could possibly be offered by the IG can't change this, since any subsidy comes short of the minimal amount of effort a strategic office-holder has to expend to implement the project, leaving at best $\kappa_{j}>0$ to be spent by him. I summarise this in the following lemma:

Lemma 3. Regardless of the IG's offer, a second period strategic office-holder does not implement the project.

Given Lemma 3, any offer by the IG would be refused by a second period strategic office-holder. The IG is then strictly better off not proposing any implementation subsidy in the second period. I summarise this in the following lemma:

\footnotetext{
${ }^{15}$ Not making this assumption would slightly complicate the exposition by adding additional subcases without adding any additional insights. See also footnote 18.

${ }^{16}$ This assumption simplifies the exposition later on: it pins down the IG's strategy which only makes an offer when it knows that the politician accepts it. An alternative way to model it would be to assume that there is an infinitesimal cost to be paid by the IG to make the offer, but that such an offer need not be paid in full if refused by the politician. This alternative would yield qualitatively equivalent results.

${ }^{17}$ Equivalent results would hold if the IG shared the voter's prior belief on the likelihood that any given politician is benevolent.
} 


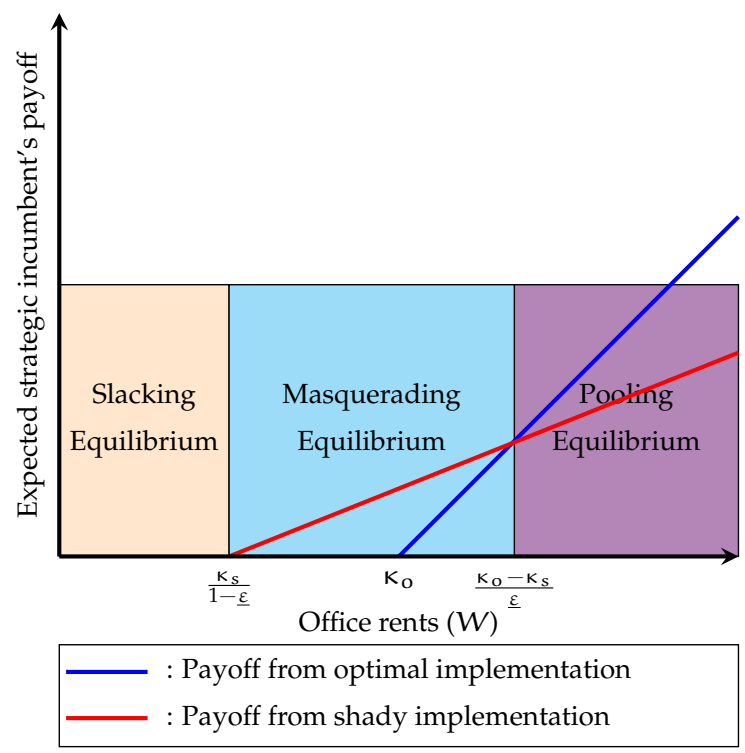

(a) Different equilibria with an inactive IG

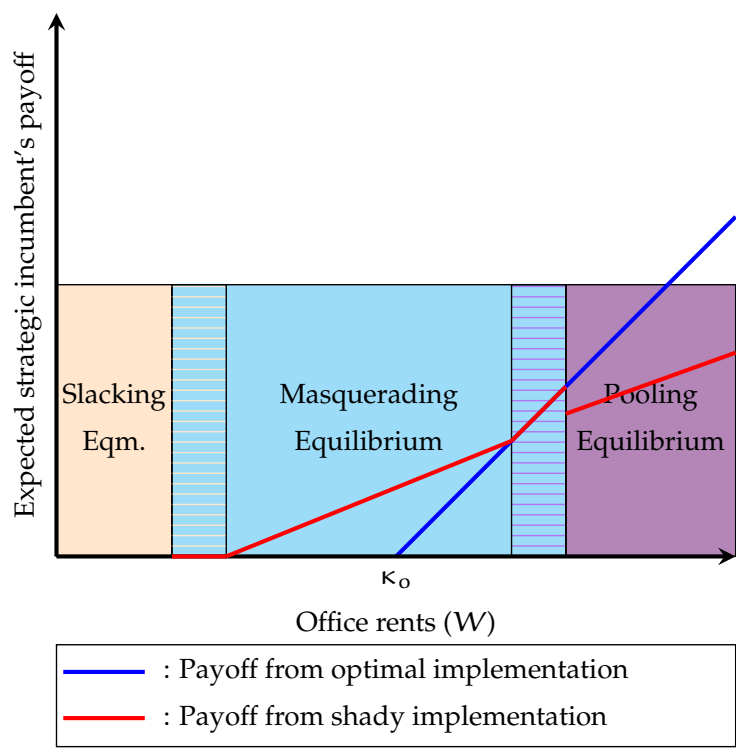

(b) Different equilibria with an active IG

Figure 2: General case with implementation subsidies

Lemma 4. In equilibrium, the IG does not propose any implementation subsidy in the second period.

Putting together the results of Lemma 3 and Lemma 4, it follows directly that Lemma 2 still holds regarding the voter's equilibrium strategy, since - slightly abusing language - a second period strategic office-holder follows the same equilibrium strategy in the modified model and in the baseline model.

As a strategic incumbent in the first period responds to electoral incentives, it is possible to draw additional insights about implementation subsidies and their welfare effects by focusing on the first period. I characterise settings in which the IG offers an implementation subsidy to a strategic incumbent in the first period in the following proposition:

Proposition 3. 1. If the equilibrium is masquerading with an inactive IG, the IG does not offer any implementation subsidy to a strategic incumbent in the first period.

2. If $\mathrm{K}_{\mathrm{o}} \geqslant \frac{\mathrm{K}_{\mathrm{s}}}{1-\varepsilon}$, for all possible values of $\mu$ there is a non-empty set of values of $\mathrm{W}$ for which the IG offers an implementation subsidy targeted towards shady implementation to a strategic incumbent in the first period. That subsidy is accepted by the strategic incumbent.

3. If $\mathrm{K}_{\mathrm{o}}<\frac{\mathrm{K}_{\mathrm{s}}}{1-\varepsilon}$, there exists a threshold $\underline{\mu}$ such that if $\mu \geqslant \underline{\mu}$, there exists a non-empty set of values of $\mathrm{W}$ for which the IG offers an implementation subsidy targeted towards shady implementation to a strategic incumbent in the first period. That subsidy is accepted by the strategic incumbent. If $\mu<\mu$, there exist no values of W such that the IG offers an implementation subsidy to a strategic incumbent in the first period.

Figure 2 provides a graphical illustration of the second part of Proposition 3 . The left panel corresponds to a setting with an inactive IG, whilst the right panel corresponds to a setting with an active IG. The blue lines represent the strategic incumbent's payoff from optimal implementation, whereas the red lines correspond to the strategic incumbent's expected payoff from shady implementation. The strategic incumbent's payoff from no implementation is equal to 0 . The pale orange areas correspond to the range of values of $W$ for which the equilibrium is slacking. The blue areas correspond to the 
range of values of $W$ for which the equilibrium is masquerading, and the blue area with pale orange (resp. purple) horizontal lines corresponds to the range of values of $\mathrm{W}$ for which the equilibrium switches from slacking (resp. pooling) to masquerading from the left panel to the right panel. The purple areas correspond to the range of values of $W$ for which the equilibrium is pooling. In the right panel the range of values of $W$ for which the equilibrium is masquerading is larger than the range of values of $W$ for which the equilibrium is masquerading in the left panel: the IG expands the range of values of $W$ for which the equilibrium is masquerading by providing implementation subsidies.

The IG does not offer an implementation subsidy when the equilibrium in the baseline model is masquerading: offering an implementation subsidy is costly, and although a strategic incumbent would accept any implementation subsidy targeted towards shady implementation in that case, the IG is better off not making an offer, since he is already implementing its favoured policy in equilibrium. By contrast, when the equilibrium in the baseline model is either pooling or slacking, the IG's intervention can affect the equilibrium. In these cases the IG, by offering an implementation subsidy targeted towards shady implementation, can lead to a switch in equilibrium, from slacking or pooling to masquerading. This can only happen if the IG's share of the project's value with shady implementation is high enough for it to be willing to offer a sufficient implementation subsidy to sway a strategic incumbent to shady implementation, and away from his preferred course of action in the baseline model.

Assume first that $\kappa_{o} \geqslant \frac{k_{s}}{1-\varepsilon}$, implying that there is an interval of values of $W$ for which the equilibrium is masquerading in the baseline model. In that case, since $\alpha$ and $\mu$ are strictly positive and by a continuity argument, there is necessarily a non-empty set of values of $W$ for which the IG is willing to subsidise shady implementation, leading to switches in equilibrium from slacking or pooling to masquerading. There are two possibly relevant constraints for the IG's ability to provide an implementation subsidy: the amount of benefits it gets from the project's shady implementation, $(1-\alpha) \mu$, and the irreducible cost for the politician under shady implementation, $\underline{\kappa}_{s}$. When neither of these constraints apply, the IG affects a strategic incumbent's equilibrium strategy.

Next, assume that $\kappa_{\mathrm{o}}<\frac{\kappa_{s}}{1-\varepsilon}$. In that case, shady implementation is strictly worse than either optimal implementation (if $W \geqslant \kappa_{\mathrm{o}}$ ) or no implementation (if $W<\kappa_{\mathrm{o}}$ ) for a strategic incumbent for all possible values of $W$. For the IG's offer to make a strategic incumbent switch to shady implementation, the offer must be sufficient to equate a strategic incumbent's expected payoff from shady implementation in the first period to his payoff from either no implementation or optimal implementation. Recall that since I select the IG preferred equilibrium, the strategic incumbent selects shady implementation in equilibrium when indifferent between it and another strategy. The value of $W$ for which the required indifference-inducing implementation subsidy is the smallest is the value of $W$ for which the payoffs of no implementation and optimal implementation are equal, $W=\kappa_{0}$. In that case, the subsidy required to make a strategic incumbent indifferent between all three actions is $\mathrm{K}_{\mathrm{s}}-(1-\varepsilon) \mathrm{\kappa}_{\mathrm{o}} \cdot{ }^{18}$ For this offer to be weakly better for the IG than not providing any implementation subsidy, it needs not to exceed the payoff which the IG derives from shady implementation:

$$
(1-\alpha) \mu \geqslant \kappa_{\mathrm{s}}-(1-\varepsilon) \kappa_{\mathrm{o}} \Leftrightarrow \mu \geqslant \underline{\mu}=\frac{\kappa_{\mathrm{s}}-(1-\varepsilon) \kappa_{\mathrm{o}}}{1-\alpha} .
$$

\footnotetext{
${ }^{18}$ Following the assumption made above, $(1-\varepsilon) \kappa_{\mathrm{o}}>\underline{\kappa_{s}}$, which ensures that the offer does not have to exceed the maximal amount possible.
} 
If this condition holds, there is a non-empty set of values of $W$ such that the IG makes a strategic incumbent switch from no implementation or optimal implementation to shady implementation. In addition, as before, there are two additional possibly relevant constraints for the IG's ability to provide implementation subsidies: the amount of benefits it gets from the project's shady implementation, $(1-\alpha) \mu$, and the irreducible cost for the politician, $\underline{\kappa_{s}}$. When neither of these constraints apply, the IG affects a strategic incumbent's equilibrium strategy.

The fact that the IG never offers an implementation subsidy targeted towards optimal implementation is not a strong positive prediction of the model, since it depends strongly on the assumption that the IG is indifferent between optimal implementation and no implementation. If the IG preferred optimal implementation over no implementation, there could be conditions under which the IG would offer an implementation subsidy targeted towards optimal implementation to a strategic incumbent in the first period. ${ }^{19}$

These results speak to current debates about the value for voters of allowing interest groups to access politicians. When access allows interest groups to provide implementation subsidies to office-holders, this can affect the types of projects that politicians implement, which has ambiguous welfare effects. Proposition 2 shows that the welfare ranking of the masquerading, pooling and slacking equilibria depends on $\varepsilon, \alpha$ and $\pi$. Since implementation subsidies can lead to switches in equilibrium, from slacking or pooling to masquerading (Proposition 3), implementation subsidies can affect the voter's welfare by leading to switches between equilibria that yield different levels of welfare for her. Such switches, and thus implementation subsidies, can be beneficial or harmful, depending on the strength of the partial control and partial screening effects in the masquerading equilibrium, the nature of the equilibrium prior to the introduction of implementation subsidies, and the voter's welfare in it. The present model thus does not provide a straightforward answer to the question of whether interest groups should be allowed to access politicians, but provides a framework to think about conditions under which such access can be beneficial or harmful to voters, emphasising the conjunction of screening and control effects.

Indeed, this conjunction of screening and control effects yields subtle results. Suppose for instance that the model's parameters are such that without the IG's intervention the equilibrium is slacking. Suppose, in addition, that the IG provides a implementation subsidy targeted towards shady implementation to a strategic incumbent in the first period. Naive thinking, solely focusing on the first period consequences, would lead to believe that because the IG has first period interests aligned with those of the voter, its intervention necessarily improves the voter's ex-ante welfare. Such a reasoning, however, is incomplete. Indeed, the IG's action can, in fact, worsen the voter's ex-ante welfare if masquerading equilibrium's partial screening effect is sufficiently strong vis-à-vis the masquerading equilibrium's partial control effect: the voter might better off without the IG's intervention, even though her interests are aligned with those of the IG. A similar argument holds for the reverse case, when the switch is from a pooling equilibrium to a masquerading equilibrium, where the voter's and IG's interests are opposed and yet the latter's intervention can improve things for the voter because it can lead to a strategic incumbent's non reelection.

Corollary 1. With implementation subsidies, a decrease in the share of the project's value which is not diverted

\footnotetext{
${ }^{19}$ This would be the case if, for instance, the equilibrium without the IG's involvement was slacking and the cost of shady implementation was sufficiently high.
} 
to the IG with shady implementation $(\alpha)$ can improve the voter's ex-ante welfare.

Corollary 2. With implementation subsidies, a decrease in the project's value ( $\mu$ ) can improve the voter's ex-ante welfare.

These two corollaries arise from the combination of Proposition 1 and Proposition 2. The mechanism that drives both of them relies on an effect on the IG's willingness to offer an implementation subsidy. The IG faces a budget constraint: it is not willing to spend more than its share of the value of the project under shady implementation, $(1-\alpha) \mu$. Consider the case where the constraint binds and the equilibrium is either pooling or slacking. Relaxing the budget constraint of the IG might allow it to provide an implementation subsidy and thereby lead to a switch to a masquerading equilibrium. The reverse also holds true: tightening the IG's budget constraint can affect the nature of the equilibrium.

Three conditions must hold for a decrease in $\alpha$ to lead to a welfare improvement for the voter: first, it must relax the IG's budget constraint, enabling it to offer an implementation subsidy in the first period to a strategic incumbent for a wider range of values of $W$; second, this change in the IG's strategy must lead to a switch in equilibrium, from a pooling or slacking equilibrium to a masquerading equilibrium; finally, the masquerading equilibrium (with the new $\alpha$ ) must welfare dominate the relevant previous equilibrium (slacking or pooling). Similarly, three conditions must hold for a decrease in $\mu$ to lead to a welfare improvement for the voter: first, it must tighten the IG's budget constraint, preventing it from offering an implementation subsidy in the first period to a strategic incumbent; second this change in the IG's strategy must lead to a switch in equilibrium, from a masquerading equilibrium to a pooling or slacking equilibrium; finally, the relevant new equilibrium (slacking or pooling) must welfare dominate the masquerading equilibrium.

Using the paper's running example helps clarify the meaning of this result and the reasoning behind it. Consider two cases: one in which the bill would create a large amount of benefits, and one in which the bill would create a small amount of benefits. Under the assumption that involved firms can't subsidise policy-making, voters' welfare is necessarily higher when the bill would create a large amount of benefits than when it would create a small amount of benefits, regardless of strategic politicians' behaviour: voters' welfare is only directly affected by the amount of benefits the bill would create, regardless of the ways in which it is written. When the involved firms can subsidise policy-making, this does not necessarily hold: in that case, voters' welfare is both directly and, possibly, indirectly affected by the amount of benefits the bill would create. The indirect effect comes from the possibility that changes in the amount of benefits the bill creates affect the willingness of the involved firms to provide implementation subsidies. It might be the case, for instance, that the firms are better off not offering implementation subsidies to politicians when the amount of benefits created by the bill are small, as their benefits from affecting the policy-making process are too small, whereas they would offer implementation subsidies to politicians when the amount of benefits created by the bill are large. This, in turn, affects voters' welfare through the nature of the policy-making choice of strategic politicians. Voters can then be better off with a small amount of benefits created by a project, provided that they gain a sufficient amount of control or screening in equilibrium when the amount of benefits is small, compared to the levels of control and screening they would benefit from when the amount of benefits is large. 


\section{Endogenous monitoring and rational ignorance}

\subsection{A modified model with endogenous monitoring}

In this section, I endogenise the voter's monitoring of office-holders. To do so, I study a setting with an exogenously given baseline monitoring level $\underline{\varepsilon}<1$ and consider the voter's incentive to increase the monitoring level, prior to the the office-holder's policy-making decision, when the cost of increasing the monitoring level to $\varepsilon \in[\underline{\varepsilon}, 1]$ is given by $\beta \times c(\varepsilon)$, with $\beta \in[0, \infty)$, and $c(\varepsilon)$ is such that $c(\underline{\varepsilon})=c^{\prime}(\underline{\varepsilon})=0$, with $c(\varepsilon)$ twice continuously differentiable, convex and strictly increasing over the interval. The policy-making process is otherwise as in the previous section. ${ }^{20}$

Modelling assumptions. Building on the preceding sections, I consider that the representative voter selects the monitoring level in this section, whereas it was exogenously given and fixed in the previous sections. This assumption can be understood or reinterpreted in several ways. First, observe that the single voter represents an electorate of multiple voters who share a similar interest in the well functioning of the political system. The information about the office-holders' performance is thus a public good: all voters want higher levels of control and screening. As shown by Bruns and Himmler (2016), the provision of this public good can be delegated to a profit-maximising media outlet. Voters are willing to pay for accountability reporting because all voters that access the media benefit from it, which in turns benefits all voters through the election's outcome. The modelling approach can be seen as a reduced form version of this mechanism and I study some important features of the optimal monitoring level in that context. An alternative re-interpretation of the modelling assumption is to consider that the choice of a monitoring level is a way to represent the decision by a benevolent leader to set up a government watchdog agency that monitors office-holders and communicates its findings to the electorate. Increasing the monitoring level at a cost then corresponds to increasing the resources available to the agency, which in turn increases the likelihood that the monitoring yields results and reveals whether implementation was done in a shady or an optimal way. ${ }^{21}$ Finally, as I discuss later, the assumption of a representative voter selecting the monitoring level she subjects office-holders to makes my paper comparable to other recent papers that tackle the issue of endogenous attention to politics, such as Prato and Wolton (2016), Prato and Wolton (2018), Trombetta (2020), or Devdariani and Hirsch (2021).

Consider again the running example of the paper and the interpretations given above. Monitoring can come from a media outlet which provides accountability reporting by paying reporters to analyse the legislative process and the contents of proposed bills, communicating the findings to voters through editorials or news articles. It can also come from an assessment of bills' contents by an independent government watchdog agency that evaluates the distribution of the benefits that would follow from the passing of a bill creating a new market or expanding an existing one. In turn, this monitoring can be used by voters to ascertain whether an office-holder has their best interests at heart or whether he pursues his own agenda.

\footnotetext{
${ }^{20}$ Although I derive the results in this section assuming that the IG can offer implementation subsidies, qualitatively similar results would hold if the IG couldn't provide implementation subsidies, as in the baseline model.

${ }^{21}$ I thank the co-editor and an anonymous referee for suggesting this additional interpretation.
} 


\subsection{Equilibrium}

In the second period, the voter does not increase the monitoring level from $\underline{\varepsilon}$ when monitoring is costly, and is indifferent between all possible monitoring levels when monitoring is costless, since they all entail the same equilibrium payoff. This follows from the conjunction of Lemma 1, Lemma 2, and Lemma 3: changes in the monitoring level can't affect the equilibrium strategy of a second period strategic office-holder since he is devoid of reputational concerns. The following lemma summarises these results:

Lemma 5. 1. Assume $\beta>0$. $\underline{\varepsilon}$ is the voter's unique optimal monitoring level in the second period.

2. Assume $\beta=0$. All monitoring levels $\varepsilon \in[\underline{\varepsilon}, 1]$ are payoff equivalent for the voter in the second period.

In the first period a strategic incumbent responds to electoral incentives, which are affected by the monitoring level: increasing the monitoring level might be profitable for the voter. The following proposition characterises when perfect monitoring is sub-optimal for the voter in the first period:

Proposition 4. 1. Assume $\beta>0$. Perfect monitoring is never optimal for the voter in the first period.

2. Assume that $\beta=0$ and that the equilibrium under $\underline{\varepsilon}$ is masquerading. If the voter's payoff from the masquerading equilibrium with the highest sustainable $\varepsilon$ is high enough, perfect monitoring in the first period is sub-optimal for the voter.

When monitoring is costly and the equilibrium under the baseline monitoring level $\underline{\varepsilon}$ is either pooling or slacking, increasing the monitoring level can't affect a strategic incumbent's first period equilibrium strategy, as it only makes shady implementation - which is already strictly dominated - less enticing. Moreover, in both pooling and slacking equilibria, the voter's ex-ante welfare is independent of the monitoring level. Thus, since a higher monitoring level is costly and does not affect the voter's payoff neither directly nor indirectly, through its effect on a strategic incumbent's equilibrium strategy, it is strictly worse for the voter than $\underline{\varepsilon}$.

The reasoning is different when monitoring is costly and the equilibrium is masquerading under the baseline monitoring level $\underline{\varepsilon}$. In that case, both the voter's ex-ante welfare and a strategic incumbent's equilibrium strategy can be affected by increases in the monitoring level: increasing the monitoring level can make the equilibrium switch from masquerading to pooling or slacking, or, if the equilibrium remains masquerading, it can increase the voter's welfare as it is an increasing function of the monitoring level in a masquerading equilibrium. Despite this, it remains sub-optimal for the voter to monitor perfectly the politician. First, if there exist a monitoring level higher than $\underline{\varepsilon}$ for which the voter's welfare from a masquerading equilibrium minus the cost of said monitoring is higher than the voter's welfare from a pooling or a slacking equilibrium (depending on the relationship between $\mathrm{K}_{\mathrm{o}}$ and $W$ ) minus the cost of monitoring, the voter is better off preserving a masquerading equilibrium. "Ignorance is bliss" for the voter: being less informed is beneficial for her, as a masquerading equilibrium wouldn't exist under perfect monitoring. Second, even if that does not hold, there are levels of imperfect monitoring that are better for the voter than perfect monitoring, following the same argument as in the previous paragraph.

The case of costless monitoring is slightly different. The main interesting result occurs when the equilibrium under the baseline monitoring level $\underline{\varepsilon}$ is masquerading. Then the voter might be better off 
monitoring imperfectly the incumbent rather than monitoring him perfectly, provided that her welfare in the masquerading equilibrium with the highest sustainable monitoring level is strictly greater than her payoff from the equilibrium that the polity would be in under perfect monitoring (pooling or slacking; the conditions under which this holds are given in Proposition 2). Here too, with costless monitoring, "ignorance is bliss" for the voter under the appropriate conditions, as a masquerading equilibrium wouldn't exist under perfect monitoring.

It is worth putting this analysis in the broader context of the recent literature on endogenous attention to policy-making, and in particular relate it to those of Prato and Wolton (2016), Prato and Wolton (2018), Trombetta (2020), and Devdariani and Hirsch (2021). First, in contrast with Trombetta (2020) and Devdariani and Hirsch (2021), my voter selects the monitoring level prior to the officeholder's action: she is concerned by both screening and control when she selects the monitoring level, while their voters are only concerned by screening when they select a monitoring level. This timing reflects the interpretations given above: institutions, like media or watchdog agencies, are set-up and funded prior to policy-making, and politicians' actions internalise this monitoring structure. Note, however, that all the results regarding the case of costly monitoring would hold in a setting where the timing of policy-making and monitoring choice would be reversed. ${ }^{22}$ What matters when the equilibrium is pooling or slacking is that the voter has no interest in increasing the monitoring level: either a strategic incumbent mimics a benevolent incumbent, in which case they are indistinguishable on the basis of the observation of the first period implementation technology, or he separates from a benevolent incumbent, in which case they are perfectly distinguishable on the basis of the observation of the first period implementation technology. Another innovation of my model is that an IG, whose interests are not those of the voter nor those of office-holders, can affect the policy-making process. Despite its presence, the voter rationally does not monitor perfectly the policy-making process when it is costly and might not even do so when it is costless. Finally, whereas all four papers consider politicians that differ in their ability, I consider politicians with heterogeneous preferences. In spite of these important modelling differences, my results relate to those of these papers: improving the voter's information about the policy-making process need not be beneficial to her, because of the effect it has on politicians' incentives, which in turn affects the information available to the voter to make her reelection decision, to both screen and control politicians.

\section{Conclusion}

In this paper I study two main questions regarding the relationships between policy-making, interest groups, and voters' welfare: first, how do interest groups affect voters' welfare and policy-making when policy-making is costly, interest groups can provide implementation subsidies to share the cost of policy-making with office-holders and extract benefits from the policy-making process at the voters' expense? Are they are harmful to voters and the well-functioning of the policy-making process in that context, or can they in fact benefit voters and improve the policy-making process? Second how should voters monitor politicians in that setting? Should they monitor perfectly office-holders to ensure satisfactory outcomes, or can imperfect monitoring be optimal?

\footnotetext{
${ }^{22}$ The results regarding the case of costless monitoring in the first period wouldn't hold, as, ex-post, a higher monitoring level can only be beneficial to the voter by allowing her to better screen politicians.
} 
To provide answers to these questions, I analyse a series of two-period political agency models with a representative voter, possibly unobserved action (moral hazard), and unobserved politicians' preferences (adverse selection). The office-holders' task is to implement projects, in each of two periods, via one of two costly technologies: a shady technology, which splits the project's value between an IG and the voter, and an optimal technology, which gives the voter the entire project's value. Politicians are either benevolent and always implement projects optimally, or strategic, selecting their strategy to maximise their own payoffs. I first consider and contrast two models with imperfect, exogenously given monitoring: one where the IG is inactive and one in which an IG can subsidise policy-making by providing an implementation subsidy to the office-holder, shouldering part of the cost of policy-making.

My analysis shows how the IG's involvement in the policy-making process can affect the voter's welfare. The voter faces a dual problem: she wants to use the reward of reelection to control office-holders and ensure that they implement her favourite action in the first period rather than their own preferred course of action; at the same time, she wants to use the election to screen an aligned incumbent from a misaligned one for the second period. The intervention of the IG in the policymaking process can lead to switches in equilibrium, from equilibria characterised by full screening and no control (a slacking equilibrium) or full control and no screening (a pooling equilibrium) to an equilibrium characterised by partial control and partial screening (a masquerading equilibrium). I provide specific conditions, depending on the strength of the partial control and partial screening effects in the masquerading equilibrium, under which the voter benefits from (resp. is harmed by) the IG's involvement in the policy-making process. Counter-intuitively, I show that an alignment of interests (resp. opposition of interests) between an IG and the voter need not imply that the former's involvement in the policy-making process is beneficial (resp. harmful) to the voter. My study thus provides a framework to think about how and when interest groups' access to politicians benefits or harms voters, through implementation subsidies that affect the policy-making process and the conjunction of screening and control effects.

In the last part of the paper, I consider a model in which the policy-making process includes an active IG and in which the voter strategically selects the monitoring level she wishes to subject office-holders to. Such monitoring can be provided, for instance, by a government watchdog agency or by a profit-maximising media. I show why a rational voter never perfectly monitor politicians when monitoring is costly. I also consider the case of costless monitoring and provide conditions under which the voter is better off imperfectly monitoring the policy-making process rather than perfectly. These results rely, on the one hand, on the coarseness of the information that the voter can derive about the incumbent's type in pooling and slacking equilibria, and on the other hand, on the possibility that "ignorance is bliss": a masquerading equilibrium, which can only exist under imperfect monitoring, can welfare dominate pooling or slacking equilibria. I derive these results under the assumption that the IG can provide implementation subsidies, but the results also hold if the IG can't get involved in the policy-making process. These results speak to concerns about voters' ignorance about policy-making. Such ignorance can, in fact, be perfectly rational (Downs (1957)), even when interest groups might influence the policy-making process and extract from it benefits at the voters' expense. 


\section{References}

Ashworth, Scott. 2012. "Electoral Accountability: Recent Theoretical and Empirical Work." Annual Review of Political Science 15:183-201.

Ashworth, Scott and Ethan Bueno de Mesquita. 2014. "Is Voter Competence Good for Voters?: Information, Rationality, and Democratic Performance." American Political Science Review 108(3):565587.

Besley, Tim. 2006. Principled Agents? The Political Economy of Good Government. Oxford: Oxford University Press.

Besley, Timothy and Marcus Smart. 2007. "Fiscal restraints and voter welfare." Journal of Public Economics 91(3-4):755-773.

Blumenthal, Benjamin. 2021. "Is More Information Good for Voters?".

Bruns, Christian and Oliver Himmler. 2016. "Mass media, instrumental information, and electoral accountability." Journal of Public Economics 134:75-84.

Canes-Wrone, Brandice, Michael C. Herron and Kenneth W. Shotts. 2001. “Leadership and Pandering: A Theory of Executive Policymaking." American Journal of Political Science 45(3):532-550.

Coate, Stephen and Stephen Morris. 1995. "On the Form of Transfers to Special Interests." Journal of Political Economy 103(6):1210-1235.

Devdariani, Saba and Alexander V. Hirsch. 2021. "Voter Attention and Electoral Accountability.".

Downs, Anthony. 1957. An Economic Theory of Democracy. New York, NY: Harper \& Row.

Duggan, John and César Martinelli. 2017. “The Political Economy of Dynamic Elections: Accountability, Commitment, and Responsiveness." Journal of Economic Literature 55(3):916-984.

Duggan, John and César Martinelli. 2020. "Electoral Accountability and Responsive Democracy." Economic Journal 130(627):675-715.

Ellis, Christopher J. and Thomas Groll. 2020. "Strategic Legislative Subsidies: Informational Lobbying and the Cost of Policy." American Political Science Review 114(1):179-205.

Fearon, James D. 1999. In Democracy, Accountability, and Representation, ed. Adam Przeworski, Susan C. Stokes and Bernard Manin. Cambridge University Press chapter "Electoral Accountability and the Control of Politicians: Selecting Good Types versus Sanctioning Poor Performance", pp. 55-97.

Fox, Justin. 2007. “Government transparency and policymaking.” Public Choice 131:23-44.

Fox, Justin and Matthew C. Stephenson. 2015. "The Constraining, Liberating, and Informational Effects of Nonbinding Law." The Journal of Law, Economics, and Organization 31(2):320-346.

Fox, Justin and Richard Van Weelden. 2012. "Costly transparency." Journal of Public Economics 96:142150. 
Fu, Qiang and Ming Li. 2014. "Reputation-concerned policy makers and institutional status quo bias." Journal of Public Economics 110:15-25.

Grossman, Gene M. and Elhanan Helpman. 2001. Special Interest Politics. Cambridge, MA: The MIT Press.

Hall, Richard L. and Alan V. Deardorff. 2006. "Lobbying as Legislative Subsidy." American Political Science Review 100(1):69-84.

Hirsch, Alexander V. and Kenneth W. Shotts. 2015. "Competitive Policy Development." American Economic Review 105(4):1646-1664.

Hirsch, Alexander V. and Kenneth W. Shotts. 2018. "Policy-Development Monopolies: Adverse Consequences and Institutional Responses." Journal of Politics 80(4):1339-1354.

Matejka, Filip and Guido Tabellini. 2021. "Electoral Competition with Rationally Inattentive Voters." Journal of the European Economic Association 19(3):1899-1935.

Prat, Andrea. 2005. “The Wrong Kind of Transparency." American Economic Review 95(3):862-877.

Prato, Carlo and Stephane Wolton. 2016. "The Voters' Curses: Why We Need Goldilocks Voters." American Journal of Political Science 60(3):726-737.

Prato, Carlo and Stephane Wolton. 2018. "Rational ignorance, populism, and reform." European Journal of Political Economy 55:119-135.

Schnakenberg, Keith E. and Ian R. Turner. 2019. "Signaling with Reform: How the Threat of Corruption Prevents Informed Policy-making." American Political Science Review 113(3):762-777.

Trombetta, Federico. 2020. "When the Light Shines Too Much. Rational Inattention and Pandering." Journal of Public Economic Theory 22(1):98-145.

Wolton, Stephane. 2019. "Are Biased Media Bad for Democracy?" American Journal of Political Science 63(3):548-562. 


\section{A Appendix}

\section{A.1 Proofs for the baseline model}

Proof of Proposition 1. Consider a strategic incumbent who employs pure strategies. ${ }^{23}$

1. If he does not implement the project in the first period, he is revealed as strategic and is not reelected, yielding a payoff of 0 .

2. If he implements the project optimally, no information can be extracted by the voter from the project's implementation and he is reelected, yielding a payoff of $W-\kappa_{0}$.

3. If he selects shady implementation, either the implementation technology is not revealed (with probability $1-\varepsilon$ ), no additional information is gained by the voter, and he is reelected; or the implementation technology is revealed (with probability $\varepsilon$ ), he is revealed as strategic, and is not reelected. This yields an expected payoff of $(1-\varepsilon) \times W-\kappa_{s}$.

Consider now the different cases outlined and the strategies prescribed in the proposition. Straightforward algebra and the assumptions made to ensure equilibrium uniqueness show that the following holds for a strategic incumbent:

1. $\mathrm{K}_{\mathrm{o}}<\frac{\mathrm{K}_{\mathrm{s}}}{1-\varepsilon}$

(a) If $W<\kappa_{0}$, both shady and optimal implementation are strictly worse than no implementation.

(b) If $\mathrm{W}=\kappa_{\mathrm{o}}$, shady implementation is worse than optimal implementation and no implementation. His payoff from no implementation and optimal implementation are equal. I select the strategy which maximises the voter's welfare, optimal implementation. ${ }^{24}$

(c) If $\mathrm{W}<\kappa_{\mathrm{o}}$, shady implementation and no implementation are strictly worse than optimal implementation.

2. $\mathrm{K}_{\mathrm{o}}=\frac{\mathrm{K}_{\mathrm{s}}}{1-\varepsilon}$

(a) If $\mathrm{W}<\mathrm{\kappa}_{\mathrm{o}}$, both shady and optimal implementation are strictly worse than no implementation.

(b) If $\mathrm{W}=\mathrm{\kappa}_{\mathrm{o}}$, he is indifferent between no implementation, shady implementation, and optimal implementation. I select the strategy which maximises the IG's payoff, shady implementation. ${ }^{25}$

(c) If $\mathrm{W}<\kappa_{\mathrm{o}}$, shady implementation and no implementation are strictly worse than optimal implementation.

3. $\frac{\kappa_{s}}{1-\varepsilon}<\kappa_{\mathrm{o}}<\frac{\kappa_{\mathrm{o}}-\kappa_{\mathrm{s}}}{\varepsilon}$

\footnotetext{
${ }^{23}$ Pure strategies are the only ones that arise in equilibrium, given the structure of the model and the equilibrium selection rules imposed which, to recall, are only relevant for a measure zero of parameters.

${ }^{24}$ This holds for mixed strategies as well.

${ }^{25}$ This holds for mixed strategies as well.
} 
(a) If $W<\frac{k_{s}}{1-\varepsilon}$, shady implementation and optimal implementation are strictly worse than no implementation for him.

(b) If $W=\frac{k_{s}}{1-\varepsilon}$, he is indifferent between no implementation and shady implementation, which are better for him than optimal implementation. I select the strategy which maximises the IG's payoff, shady implementation. ${ }^{26}$

(c) If $\frac{k_{s}}{1-\varepsilon}<W<\frac{k_{0}-k_{s}}{\varepsilon}$, optimal implementation and no implementation are strictly worse than shady implementation for him.

(d) If $W=\frac{\kappa_{0}-\kappa_{s}}{\varepsilon}$, he is indifferent between optimal implementation and shady implementation, which are better for him than no implementation. I select the strategy which maximises the IG's payoff, shady implementation. ${ }^{27}$

(e) If $W>\frac{k_{0}-k_{s}}{\varepsilon}$, shady implementation and no implementation are strictly worse than optimal implementation for him.

Proof of Proposition 2. In a slacking equilibrium, benevolent politicians optimally implement a project in both periods whereas strategic politicians do not implement a project in either period. A benevolent incumbent is reelected, whilst a strategic incumbent is ousted. The voter's ex-ante welfare in a slacking equilibrium is thus equal to:

$$
\pi \times 2 \mu+(1-\pi)(\pi \times \mu) .
$$

In a masquerading equilibrium, benevolent politicians optimally implement a project in both periods whereas a strategic incumbent implements the project with the shady implementation technology in the first period, and a second period strategic office-holder does not implement the project. A benevolent incumbent is reelected, whilst a strategic incumbent is reelected with probability $1-\varepsilon$ and ousted with probability $\varepsilon$. The voter's ex-ante welfare in a masquerading equilibrium is thus equal to:

$$
\pi \times 2 \mu+(1-\pi)(\alpha \mu+\varepsilon \pi \mu)
$$

In a pooling equilibrium, both strategic and benevolent incumbents optimally implement the project in the first period; a benevolent second period office-holder optimally implements the project, while a strategic second period office-holder does not implement the project. Both benevolent and strategic incumbents are reelected. The voter's ex-ante welfare in a pooling equilibrium is thus equal to:

$$
\pi \times 2 \mu+(1-\pi)(\mu) .
$$

Straightforward algebra shows that the masquerading equilibrium welfare dominates the slacking equilibrium if and only if $\alpha+\varepsilon \times \pi>\pi$ and the masquerading equilibrium welfare dominates the pooling equilibrium if and only if $\alpha+\varepsilon \times \pi>1$.

\footnotetext{
${ }^{26}$ This holds for mixed strategies as well.

${ }^{27}$ This holds for mixed strategies as well.
} 


\section{A.2 Proofs for the model with implementation subsidies}

Proof of Proposition 3. In what follows, I prove the second and third cases of the proposition as the first case of the proposition follows from the exposition in the main text.

2. If $\kappa_{\mathrm{o}} \geqslant \frac{\kappa_{\mathrm{s}}}{1-\varepsilon}$, for all possible values of $\mu$ there is a non-empty set of values of $W$ for which the IG offers an implementation subsidy targeted towards shady implementation to a strategic incumbent in the first period. That subsidy is accepted by the strategic incumbent.

Recall the results of Proposition 1:

1. If $\kappa_{\mathrm{o}} \geqslant \frac{\kappa_{s}}{1-\varepsilon}$ : for all $W<\frac{\kappa_{s}}{1-\varepsilon}$, the unique equilibrium is slacking; for $\frac{\kappa_{s}}{1-\varepsilon} \leqslant W \leqslant \frac{\kappa_{0}-\kappa_{s}}{\varepsilon}$ the unique equilibrium is masquerading; and for all $W>\frac{k_{0}-k_{s}}{\varepsilon}$, the unique equilibrium is pooling.

Offering an implementation subsidy targeted towards optimal implementation can't be an equilibrium strategy for the IG, as it is indifferent between optimal implementation and no implementation. Consider next the desirability of an implementation subsidy targeted towards shady implementation. There are two possibly relevant upper bounds on the amount of the implementation subsidy offered by the IG. First the IG is at most willing to spend in implementation subsidy precisely what it gains from the implementation of the shady project, $(1-\alpha) \mu$. Moreover, the implementation subsidy might be bounded from above by the minimal amount of effort that cannot be subsidised by the IG, $\kappa_{s}$.

Define $m(W)$, the minimal amount of the offer required to make a strategic incumbent indifferent between shady implementation and either optimal implementation or no implementation. If $\frac{\kappa_{s}}{1-\varepsilon} \leqslant W \leqslant \frac{\kappa_{0}-\kappa_{s}}{\varepsilon}, m(W)=0$. If $W<\frac{\kappa_{s}}{1-\varepsilon}, m(W)=\kappa_{s}-(1-\varepsilon) W$. If $W>\frac{\kappa_{0}-\kappa_{s}}{\varepsilon}$, $m(W)=\kappa_{s}-\kappa_{o}+\varepsilon W$. Since $(1-\alpha) \mu>0$, there always exist a non-empty set of values of $W$ for which the IG is willing to match $m(W)$ when it is positive. By a similar argument, there exists a non-empty set of values of $W$ for which the other relevant constraint (the irreducible cost that must be paid by the politician) holds. The intersection of these sets is non empty, concluding the proof.

3. If $\kappa_{\mathrm{o}}<\frac{\kappa_{s}}{1-\varepsilon}$, there exists a threshold $\underline{\mu}$ such that if $\mu \geqslant \underline{\mu}$, there exists a non-empty set of values of $W$ for which the IG offers an implementation subsidy targeted towards shady implementation to a strategic incumbent in the first period. That subsidy is accepted by the strategic incumbent. If $\mu<\underline{\mu}$, there exist no values of $W$ such that the IG offers an implementation subsidy to a strategic incumbent in the first period.

Define again $m(W)$, the minimal amount of implementation subsidy required to make a strategic incumbent indifferent between shady implementation and either optimal or no implementation. If $W<\kappa_{0}, m(W)=\kappa_{s}-(1-\varepsilon) W$ and if $W \geqslant \kappa_{0}, m(W)=\kappa_{s}-\kappa_{o}+\varepsilon W$. Next, define $\underline{\mu}=\frac{\kappa_{s}-(1-\varepsilon) \kappa_{0}}{1-\alpha}$. Assume $\mu<\underline{\mu}$. If $\mu<\underline{\mu}$, the IG's budget constraint is violated at $W=\kappa_{0}$ (where it is the cheapest for the IG to induce indifference), as $(1-\alpha) \mu-\kappa_{\mathrm{s}}+\kappa_{\mathrm{o}}-\varepsilon \kappa_{\mathrm{o}}<(1-\alpha) \underline{\mu}-\kappa_{\mathrm{s}}+\kappa_{\mathrm{o}}-\varepsilon \kappa_{\mathrm{o}}=0$. Next, assume $\mu \geqslant \mu$. In that case the IG's budget constraint holds at $W=\kappa_{0}$. Additionally, observe that the value of the minimal indifference-inducing implementation subsidy at $\kappa_{\mathrm{o}}$ is equal to $\kappa_{\mathrm{s}}-(1-\varepsilon) \kappa_{\mathrm{o}}$, implying that the strategic incumbent still has to expend $(1-\varepsilon) \kappa_{\mathrm{o}}$, which is greater than $\underline{\kappa_{\mathrm{s}}}$ by assumption. 


\section{A.3 Proofs for the model with endogenous monitoring}

Proof of Proposition 4.

1. Assume $\beta>0$. Perfect monitoring is never optimal for the voter in the first period.

I consider only the case of a masquerading equilibrium here as the case of slacking and pooling equilibria is detailed in the main text. I denote by $\tilde{\varepsilon}\left(W, \mu, \alpha, \underline{\kappa_{s}}\right)$ the value of $\varepsilon$ given the values of $W$ $\mu, \alpha$, and $\underline{\kappa_{s}}$ for which a strategic politician's expected payoff from shady implementation is equal to his payoff from optimal implementation (if $W \geqslant \kappa_{\mathrm{o}}$ ) or from no implementation (if $W<\kappa_{\mathrm{o}}$ ), taking as given the IG's equilibrium strategy in both periods. $\tilde{\varepsilon}\left(W, \mu, \alpha, \underline{\kappa_{s}}\right)$ is defined for every possible $W$ and is strictly between 0 and $1\left(\left[\tilde{\varepsilon}\left(W, \mu, \alpha, \underline{k_{s}}\right), 1\right]\right.$ is thus not a singleton interval). In what follows the voter's welfare refers, slightly abusing language, to the voter's welfare from policy-making (not taking into account the monitoring cost). Define the the voter's welfare from the slacking and the pooling equilibrium minus the cost of $\left.\tilde{\varepsilon}\left(W, \mu, \alpha, \underline{\kappa_{s}}\right)\right)$ as:

$$
\begin{aligned}
& \Pi^{s}\left[\tilde{\varepsilon}\left(W, \mu, \alpha, \underline{k_{s}}\right)\right]=\pi \times 2 \mu+(1-\pi)(\pi \times \mu)-\beta \times c\left(\tilde{\varepsilon}\left(W, \mu, \alpha, \underline{k_{s}}\right)\right) \\
& \Pi^{p}\left[\tilde{\varepsilon}\left(W, \mu, \alpha, \underline{k_{s}}\right)\right]=\pi \times 2 \mu+(1-\pi)(\mu)-\beta \times c\left(\tilde{\varepsilon}\left(W, \mu, \alpha, \underline{k_{s}}\right)\right.
\end{aligned}
$$

Finally, define the voter's welfare from the masquerading equilibrium for $\varepsilon$, minus $\varepsilon$ 's cost as:

$$
\Pi^{\mathrm{m}}[\varepsilon]=\pi \times 2 \mu+(1-\pi)(\alpha \mu+\varepsilon \pi \mu)-\beta \times c(\varepsilon) .
$$

I now tackle the case of a masquerading equilibrium when monitoring is costly via a series of claims.

Claim: There exists a unique $\hat{\varepsilon}$ which maximises $\Pi^{\mathrm{m}}[\varepsilon]$ on $\left[\underline{\varepsilon}, \tilde{\varepsilon}\left(W, \mu, \alpha, \underline{\mathrm{K}_{\mathrm{s}}}\right)\right]$.

Proof: Since $c(\varepsilon)$ is strictly convex, $\Pi^{\mathrm{m}}[\varepsilon]$ is strictly concave on $\left[\underline{\varepsilon}, \tilde{\varepsilon}\left(W, \mu, \alpha, \underline{\kappa_{s}}\right)\right] . \Pi^{m}[\varepsilon]$ is twice continuously differentiable on $\left[\underline{\varepsilon}, \tilde{\varepsilon}\left(W, \mu, \alpha, \underline{\kappa_{s}}\right)\right]$. There are then two possible cases and two subcases:

1. If $\underline{\varepsilon}=\tilde{\varepsilon}\left(W, \mu, \alpha, \underline{k_{s}}\right), \hat{\varepsilon}=\underline{\varepsilon}$ (and its uniqueness follows).

2. If $\underline{\varepsilon}<\tilde{\varepsilon}\left(W, \mu, \alpha, \underline{\kappa_{s}}\right): \frac{\partial \Pi^{m}[\underline{\varepsilon}]}{\partial \varepsilon}>0$, since $c^{\prime}(\underline{\varepsilon})=0$ and $(1-\pi) \pi \mu>0$.

(a) If $\frac{\partial \Pi^{\mathrm{m}}[\varepsilon(\tilde{W})]}{\partial \varepsilon} \leqslant 0$, by the strict monotonicity of $\frac{\partial \Pi^{\mathrm{m}}[\varepsilon]}{\partial \varepsilon}$ and the Intermediate Value Theorem, there exists a unique $\varepsilon$ for which $\frac{\partial \Pi^{\mathrm{m}}[\varepsilon]}{\partial \varepsilon}=0$. Since $\Pi^{\mathrm{m}}[\varepsilon]$ is strictly concave, $\Pi^{\mathrm{m}}[\varepsilon]$ is maximised on $\left[\underline{\varepsilon}, \tilde{\varepsilon}\left(W, \mu, \alpha, \underline{\kappa_{s}}\right)\right]$ for this $\varepsilon$. Call $\hat{\varepsilon}$ this $\varepsilon$, which concludes this subcase.

(b) If $\frac{\partial \Pi^{\mathfrak{m}}[\varepsilon(\tilde{W})]}{\partial \varepsilon}>0$, by the strict monotonicity of $\frac{\partial \Pi^{\mathfrak{m}}[\varepsilon]}{\partial \varepsilon}, \Pi^{\mathfrak{m}}[\varepsilon]$ is increasing over the entire interval $\left[\underline{\varepsilon}, \tilde{\varepsilon}\left(W, \mu, \alpha, \underline{\kappa_{s}}\right)\right]$ and takes its global maximum at $\tilde{\varepsilon}\left(W, \mu, \alpha, \underline{\kappa_{s}}\right)$. Define $\hat{\varepsilon}=$ $\tilde{\varepsilon}\left(W, \mu, \alpha, \underline{\kappa_{s}}\right)$, which concludes this subcase.

I now show that perfect monitoring is never optimal.

1. $W<\kappa_{o}$ and $\Pi^{m}[\hat{\varepsilon}] \geqslant \Pi^{s}\left[\tilde{\varepsilon}\left(W, \mu, \alpha, \underline{\kappa_{s}}\right)\right]$ or $W \geqslant \kappa_{o}$ and $\Pi^{m}[\hat{\varepsilon}] \geqslant \Pi^{p}\left[\tilde{\varepsilon}\left(W, \mu, \alpha, \underline{k_{s}}\right)\right]$.

Claim: $\hat{\varepsilon}$ is optimal for the voter.

Proof: Assume $W \geqslant \kappa_{o}$ (the reasoning is the same for $W<\kappa_{o}$ ). If $\Pi^{m}[\hat{\varepsilon}] \geqslant \Pi^{\mathfrak{p}}\left[\tilde{\varepsilon}\left(W, \mu, \alpha, \underline{\kappa_{s}}\right)\right]$, the voter's welfare from a masquerading equilibrium minus the cost of $\hat{\varepsilon}$ is higher than the voter's welfare in a pooling equilibrium minus the cost of $\tilde{\varepsilon}\left(W, \mu, \alpha, k_{s}\right)$. As the voter's welfare 
net of the monitoring cost in any pooling equilibrium is strictly less than $\Pi^{\mathfrak{p}}\left[\tilde{\varepsilon}\left(W, \mu, \alpha, \underline{\kappa_{s}}\right)\right]$ (since any pooling equilibrium can only be reached for an $\left.\varepsilon>\tilde{\varepsilon}\left(W, \mu, \alpha, \underline{\kappa_{s}}\right)\right)$, $\hat{\varepsilon}$ is optimal for the voter on $[\underline{\varepsilon}, 1]$.

2. $W<\kappa_{o}$ and $\Pi^{m}[\hat{\varepsilon}]<\Pi^{s}\left[\tilde{\varepsilon}\left(W, \mu, \alpha, \underline{\kappa_{s}}\right)\right]$, or $W \geqslant \kappa_{o}$ and $\Pi^{m}[\hat{\varepsilon}]<\Pi^{p}\left[\tilde{\varepsilon}\left(W, \mu, \alpha, \underline{\kappa_{s}}\right)\right]$.

Claim: There exists a non empty set of values of $\varepsilon$ greater than $\tilde{\varepsilon}\left(W, \mu, \alpha, \underline{k_{s}}\right)$ for which the voter is better off than with imperfect monitoring than perfect monitoring.

Proof: Assume $W \geqslant \kappa_{0}$ (the reasoning is the same for $W<\kappa_{0}$ ). Define:

$$
\zeta(\varepsilon)=\Pi^{\mathrm{m}}[\hat{\varepsilon}]-\Pi^{\mathrm{p}}[\varepsilon] .
$$

$\zeta\left(\tilde{\varepsilon}\left(W, \mu, \alpha, \underline{\kappa_{s}}\right)\right)<0$, by definition. Next, either $\zeta(1) \geqslant 0$ or $\zeta(1)<0$. If the latter holds, the voter is better off with any monitoring level $\varepsilon \in\left(\tilde{\varepsilon}\left(W, \mu, \alpha, \underline{\kappa_{s}}\right), 1\right]$ than with $\hat{\varepsilon}$. Since $\left(\tilde{\varepsilon}\left(W, \mu, \alpha, \underline{\kappa_{s}}\right), 1\right]$ is a non empty, non singleton interval, there are values of $\varepsilon<1$ such that imperfect monitoring is better for the voter than perfect monitoring. If the former holds, there exists a value of $\varepsilon$, which I denote $\varepsilon_{\Delta}$, such that $\zeta\left(\varepsilon_{\Delta}\right)=0$ (from the Intermediate Value Theorem). The voter is then better off with an imperfect monitoring level $\varepsilon \in\left(\tilde{\varepsilon}\left(W, \mu, \alpha, \underline{\kappa_{s}}, \varepsilon_{\Delta}\right)\right.$ than with perfect monitoring.

2. Assume that $\beta=0$ and that the equilibrium under $\underline{\varepsilon}$ is masquerading. If the voter's payoff from the masquerading equilibrium with the highest sustainable $\varepsilon$ is high enough, perfect monitoring in the first period is sub-optimal for the voter.

The highest sustainable level of $\varepsilon$ such that the equilibrium is masquerading is $\tilde{\varepsilon}\left(W, \mu, \alpha, \underline{\kappa_{s}}\right)$. The voter's ex-ante welfare when $\varepsilon=\tilde{\varepsilon}\left(W, \mu, \alpha, \underline{\kappa_{s}}\right)$ is $\pi \times 2 \mu+(1-\pi)\left(\alpha \mu+\tilde{\varepsilon}\left(W, \mu, \alpha, \underline{\kappa_{s}}\right) \pi \mu\right)$. Using the results of Proposition 2, perfect monitoring is strictly worse for the voter than a level $\tilde{\varepsilon}\left(W, \mu, \alpha, \underline{\kappa_{s}}\right)$ of monitoring whenever:

$$
\begin{cases}\alpha+\tilde{\varepsilon}\left(W, \mu, \alpha, \underline{\kappa_{s}}\right) \times \pi>1 & \text { if } W \geqslant \kappa_{o} \\ \alpha+\tilde{\varepsilon}\left(W, \mu, \alpha, \underline{\kappa_{s}}\right) \times \pi>\pi & \text { if } W<\kappa_{o}\end{cases}
$$

